radiotherapy at the Children's Hospital, Philadelphia, PA. Fourteen children also received adjuvant chemotherapy. A significant drop in IQ was seen among children with non-cortical tumors who received whole-brain radiotherapy with or without chemotherapy and who were treated before age 7. IQ did not decrease significantly in survivors treated after age 7. The IQ fell from a baseline of 104 to 92 at follow-up (Radcliffe J et al. Three- and four-year cognitive outcome in children with noncortical brain tumors treated with whole-brain radiotherapy. Ann of Neurol Oct 1992; 32:551-554). (Correspondence: Dr. Radcliffe, Division of Child Development and Rehabilitation, Children's Seashore House, 3405 Civic Center Boulevard, Philadelphia, PA 19104.)

COMMENT. All children younger than 7 years in this group were receiving special education at follow-up and $50 \%$ of the children over 7 years at diagnosis were receiving supplemental educational services. Increased fatiguability could be another reason for the poor school performance in these children.

\title{
LONG-TERM NEUROLOGIC PROBLEMS WITH MEDULLOBLASTOMA
}

All 11 children who presented since 1976 in Cardiff, Wales with medulloblastoma and who had survived at least 5 years were reviewed neurologically. Current ages ranged from $10-24$ years. Surgical removal was complete in 6 . All received radiotherapy. Nine had additional chemotherapy. Mild cerebellar ataxia was present in 10 , and external ocular movement abnormalities in 2. Signs attributable to therapy were optic atrophy in 2, fine motor incoordination in 2, dyspraxia in 7 and dementia in 1 . Epilepsy occurred in 2. Only 1 patient who presented at 13 years was free of neurologic consequences of therapy. Only 2 attended grade school, and only 3 are gainfully employed (Walace SJ, Salaman PF. Long-term neurologic problems of children treated with medulloblastoma. Pediatr Neurol Sept/Oct 1992; 8:386-387 (abstract)). (Correspondence: Dr. Sheila J. Wallace, Department of Pediatrics, University Hospital of Wales, Health Park, Cardiff, CF44XN Wales UK.)

COMMENT. Detection of tumor occurrence by surveillance scanning in children with medulloblastoma is reported from the Children's Hospital of Philadelphia. Surveillance brain scans failed to detect recurrent disease in most patients and had virtually no impact on outcome. Follow-up should emphasize parent education and neurologic evaluation to detect relapse and to elicit and remediate late effects of therapy (Torres C et al. Ann Neurol Sept 1992; 32:458 (abstract)).

The antineoplastic effects of gallium nitrate on human medulloblastoma in vivo are reported from the Medical College of Wisconsin, Milwaukee, WI (Whelan HT et al. Pediatr Neurol Sept/Oct $1992 ; \underline{8}: 323-327)$. Mice injected intradermally with medulloblastoma Daoy cell line developed tumors. Gallium nitrate treatment reduced tumor growth rate and tumor size, but the animals suffered nephrotoxicity. 